\title{
DISTINCTIVE FEATURES OF ORALITY IN A MICROLANGUAGE: THE ITALIAN LANGUAGE IN THE PLENARY SESSIONS OF THE EUROPEAN PARLIAMENT. SOME PRELIMINARY OBSERVATIONS
}

\author{
Michela Bertozzi \\ michela.bertozzi6@unibo.it \\ Università di Bologna (Forlì)
}

\begin{abstract}
The aim of this observational study is to examine which distinctive features of orality can be found in a particularly interesting microlanguage (Serianni 2004; Marzocchi 1998): the Italian spoken by the members of the European Parliament (EP) in the plenary sessions. To detect these phenomena, a micro-corpus of original Italian speeches delivered at the EP was built; this data collection phase was followed by the analysis of the most significant features of orality, with particular reference to unmodified loanwords, the use of acronyms or procedural routines and formulas used (Marzocchi 2005), as well as all those lexical and syntactic elements putting a strain on oral language (Bakti 2009, Tissi 2000). The observation of the distinctive features of oral language is ultimately aimed at using these data in the teaching of interpreting, a discipline that cannot ignore a fundamental paradigm: a quality interpreted speech is necessarily linked to a deep knowledge of the typical oral features of the source (micro)language.
\end{abstract}

\section{Riassunto}

Lobiettivo di questo studio osservativo è analizzare quali tratti tipici dell'oralità caratterizzano una microlingua (Serianni 2004) particolarmente interessante: l'italiano parlato dai membri del Parlamento europeo (PE) nell'ambito delle sessioni plenarie. Per individuare questi fenomeni si è provveduto a creare un micro-corpus di discorsi originali italiani pronunciati al PE; la fase di raccolta dei discorsi è stata seguita dall'analisi dei tratti più significativi legati all'oralità, con particolare riferimento a prestiti integrali non modificati, l'uso di sigle o procedure tipiche del PE (Marzocchi 2005) e tutti quegli elementi lessicali e sintattici che caratterizzano fortemente il discorso 
orale (Bakti 2009, Tissi 2000). L'osservazione dei tratti tipici di una microlingua orale è, in ultima analisi, volta a un possibile utilizzo di questi dati nell'ambito della didattica dell'interpretazione, disciplina che non può prescindere da un paradigma di base: un discorso interpretato di qualità è necessariamente legato ad un'approfondita conoscenza dei tratti orali tipici della (micro)lingua di partenza.

Keywords: Orality. European Parliament. Italian. Plenary.

Parole chiave: Oralità. Parlamento Europeo. Italiano. Plenaria.

Manuscript received on April 13, 2015 and accepted for publication on September $29,2015$. 


\section{Research objectives}

The aim of this observational corpus-driven research is to examine which distinctive features of orality can be found in a particularly interesting microlanguage: the language spoken by the Italian members of the European Parliament (EP) in a very specific and well-codified context, the plenary session. This setting entails a whole series of different variables which must be taken into consideration by the interpreter, such as the monologic format, the addressor, the outcomes and goals, the message and the content or the genre, among other elements (Angelelli 2000). In the literature, considerable attention has been devoted to the specific codified characteristics of this setting the plenary session, which is deemed to be "the apex of an interpreter's work at the European Parliament" (Marzocchi 1998: 69). However, very limited research has been carried out on the way in which these characteristics affect interpreting in terms of constraints and expectations, as well as the possible implications of language-specific components within the same setting. On the one hand, research is needed on:

a wide range of statutory goals, memberships and organizational setups. Their impact on patterns of communication, on prevailing language functions and text types and in turn on interpreting [...] deserves a more detailed and systematic analysis. Research seems therefore to be needed into the extent to which the specific organization and underlying cultural assumptions of institutions [...] put varying constraints on interpreting. (Marzocchi 1998: 52)

On the other hand, it is not possible to provide a thorough insight into these institution-specific elements affecting interpreting without a language-dependent, orality-driven approach based on the assumption that any high quality target speech must be linked to a deep knowledge of the specific features of the source speech. Little research has been conducted on the connections between the typical characteristics of orality in a defined setting from a language-specific perspective and their possible impact on the interpreter's performance and on the users' expectations.

Against this backdrop, this study aims at providing some preliminary indications on the main characteristics of the Italian spoken in the EP plenary sessions, starting from the analysis of a small corpus of original Italian 
speeches delivered in that setting between 2004 and 2011; this preliminary observation may serve multiple purposes, since the ultimate long-term goal of this study is to shed light on the implications of these setting-specific and language-dependent characteristics of the (Italian) source speech, paving the way to possible future studies on the analysis of the output (Italian>Spanish simultaneous interpretation) considering the aforementioned variables and any possible didactic implications for interpreting trainees.

\section{The EP plenary session}

\subsection{Preliminary practical considerations}

Before analyzing the structure of this setting, its mechanisms and its main distinctive features, a few preliminary considerations have been made from a practical perspective: since this research is based on the assumption that this kind of oral language observation is not corpus-based but rather corpus-driven (Tognini Bonelli 2001), particular attention has been devoted to the phase in which the corpus was built (see § 3 ).

Given the endemic difficulties in finding suitable material for interpreting corpora design, one of the factors that have been taken into consideration when building this corpus has been the availability and easy access to audio and video files of the original and interpreted speeches. This aspect may seem negligible, but it is in fact important since very few interpreting corpora (Setton 2011) provide access to a large number of source and target speeches with their related transcriptions, delivered in the same setting and sharing a whole set of variables (see $\S 4$ ) thus allowing for a direct comparison between the two versions of the same speech. ${ }^{1}$

The EP Television ${ }^{2}$ platform provides online access to all the audio and video files of the plenary sessions divided by date, topic and speaker; moreover, a pull-down menu allows users to choose the language of the interpreted version and even download it, bearing in mind that "the interpretation does not constitute an authentic record of proceedings", as indicated in the disclaimer (fig. 1):

1. Among them, see EPIC - European Parliament Interpreting Corpus (Russo et al. 2006), corpus DIRSI (Bendazzoli 2010), corpus IMITES (Spinolo 2014), corpus EPTIC (Bernardini, Ferraresi and Milicevic 2013), corpus EPICG (Defrancq 2015).

2. http://www.europarltv.europa.eu/en/home.aspx (last consulted 24/03/15) 


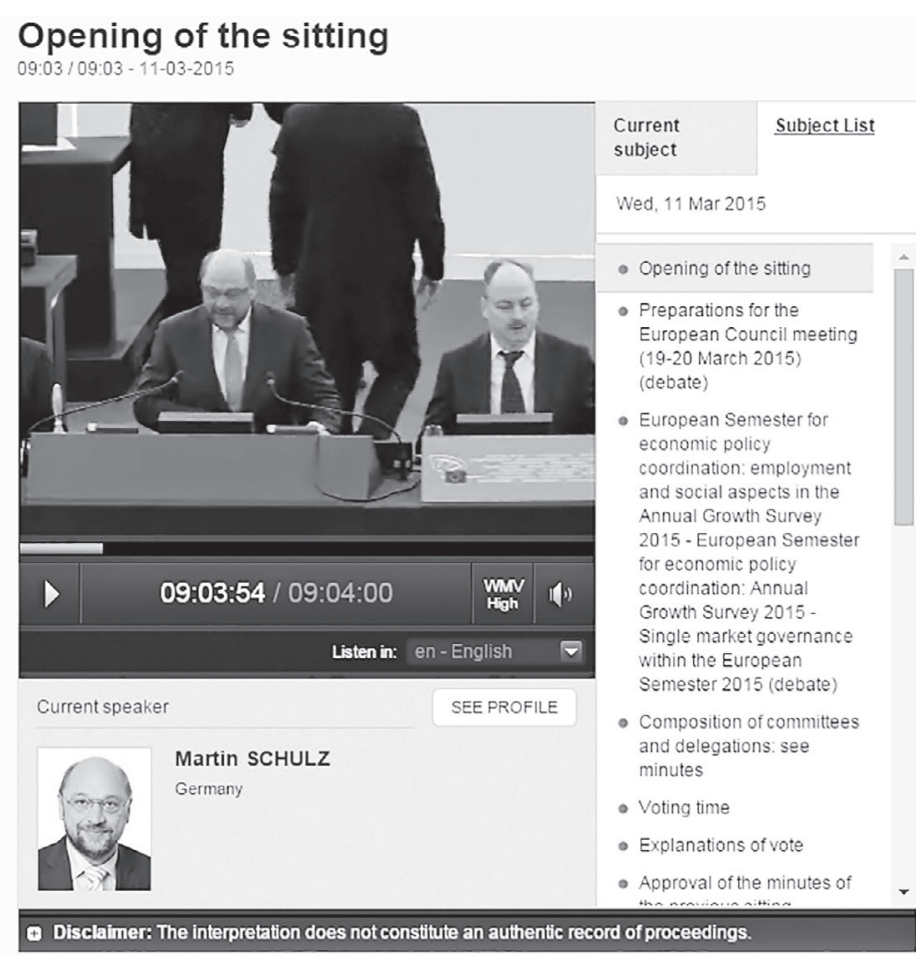

Figure 1. EP Television

Moreover, the EP Register of Documents ${ }^{3}$ online platform contains a repository of all the plenary sessions and their verbatim reports; in this way, the often time-consuming and complex transcription activity is streamlined, providing more material and improving quality in the corpus design. It is also worth remembering that, for the purposes of the present corpus, part of the original speeches has been taken from an existing corpus of reference, EPIC - European Parliament Interpreting Corpus, a trilingual parallel interpreting corpus compiled at the University of Bologna at Forli (Russo \& al. 2012).

\subsection{Structure of the plenary session}

The motivations underlying the decision to observe orality and its features in plenary sessions are not only linked to practical considerations but, above all,

3. http://www.europarl.europa.eu/RegistreWeb/search/simpleSearchHome.htm?language= EN (last consulted 24/03/15) 
to the peculiar structure of this very formal and prestigious event. As stated in the previous section:

the apex of an interpreter's work at the EP, both in terms of peer recognition and in terms of effort, is the monthly plenary assembly, although it is by no means the setting where a smooth, bi-directional flow of communication is most crucial. [...] Apart from the occasional controversy on points of procedure or personal matters, spontaneous discussion no longer takes place at this stage. (Marzocchi 1998: 69)

Albeit enjoying the most widespread prestige and respect, the highest point in the European democratic process has rather become an institutionalized and extremely formalized event, where debate is limited to a minimum, turn-taking must be scheduled well in advance, most speeches are prepared and read at a considerable speed, and comments or replies are often merely short requests for clarifications. The fact that this setting combines the typical features of spontaneous speech and written language makes these speeches particularly interesting from the perspective of orality.

The structure of a typical plenary session is reported hereunder:

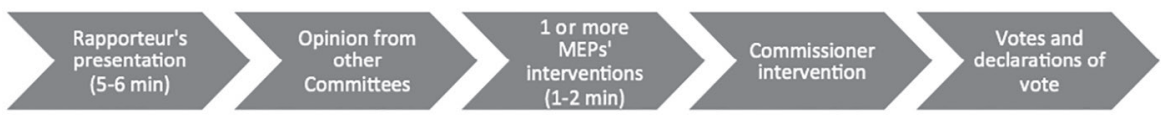

Figure 2. A typical plenary session

The first part is usually a short presentation by the main rapporteur on the piece of legislation to be approved, followed by the opinion from other Committees and one or more MEPs' interventions (speaking time is allocated according to the proportion of the political group, resulting in very short speeches: one or two minutes on average). Then, a European Commissioner usually takes the floor, followed by the declarations of vote and the vote itself.

Hence, the main language-independent features of the plenary session as an oral discourse are early speech planning and scheduling, limited spontaneous debate, institutionalized turn-taking management, very formal setting, presence of extremely short speeches, which leads to a strong incidence of written-to-be-read texts, specific prosody, less redundancy (a characteristic feature of impromptu speeches), complex syntax and high speaking speed. All these elements cannot but affect the interpreter's understanding and processing of the source speech, thus having an influence also on the delivery. That is why the language spoken within the EP plenary session 
may be regarded as a microlanguage, since it is an umbrella term indicating those specialized or technical languages used in certain specific sectors and domains, having their own typical characteristics at a lexical (own terminology, prevalence of monosemy over polysemy) and morphosyntactic (preference for some syntactic structures, specific formulas, etc.) level. Cambiaghi's (1988: 187) definition of microlanguage is especially suitable for the purposes of the present research:

microlingue (prodotte cioè dalla selezione all'interno di tutte le componenti della competenza comunicativa in una lingua) usate nei settori scientifici (ricerca, università) e professionali (dall'operaio all'ingegnere, dall'infermiere al medico, dallo studente di liceo al critico letterario) con gli scopi di comunicare nella maniera meno ambigua possibile e di essere riconosciuti come appartenenti ad un settore scientifico o professionale.

\section{Corpus of reference}

After the definition of the research objectives and the methodological assumptions underlying the whole study (which is part of the author's ongoing $\mathrm{PhD}$ project), we have moved to the compilation of a small corpus of original Italian speeches delivered at the EP within plenary sessions between 2004 and 2011. The final composition of the corpus consists of 39 original speeches, all of them sharing a common feature: they have been interpreted into Spanish; this is a relevant point since one of the long-term future objectives of this project is to provide possible didactic tools for interpreting trainees from Italian into Spanish, but the same approach can obviously be applied to other language combinations as well, given that the EP Television platform provides the recordings of other interpreted versions of the same speeches.

The total length of the speeches that have been analyzed is 175.75 minutes, and they all come from the same online platform. Despite the relatively limited size of the corpus, it must be considered that, for a small specific study on language-bound characteristics within an even more restricted context, this data is suitable to serve the purpose of observing the most noticeable features of the Italian spoken by this small group (Italian mother tongue members of the EP) within a very limited setting (the plenary session), thus laying the foundation for future analyses. These speeches have been transcribed following the EPIC (Russo et al. 2006) transcription norms, and the following variables have been observed for each speech: 


\begin{tabular}{|c|c|}
\hline $\begin{array}{l}\text { VARIABLES } \\
\text { ANALYZED }\end{array}$ & Values \\
\hline Date & \\
\hline Speech code & \\
\hline Language & \\
\hline Duration & Short $(<120 \mathrm{sec})$, medium $(121-360)$, long $(>360)$ \\
\hline Length & Short (<300 words), medium (301-1000), long (>1000) \\
\hline Speed & Low $(<100$ words/min), medium $(100-120)$, high $(>120)$ \\
\hline $\begin{array}{l}\text { Type of } \\
\text { delivery }\end{array}$ & Impromptu, mixed, read \\
\hline $\begin{array}{l}\text { Speaker's } \\
\text { name and } \\
\text { surname } \\
\text { Gender } \\
\text { Country } \\
\text { Mother tongue } \\
\text { Political } \\
\text { function } \\
\text { Political group } \\
\text { Topic } \\
\text { Possible } \\
\text { comments/ } \\
\text { problems }\end{array}$ & $\begin{array}{l}\text { MEP, Chairman, President of the EP, Vice-president, Commissioner, } \\
\text { guest } \\
\text { Agriculture and fisheries, economics and finance, employment, } \\
\text { environment, health, justice, politics, procedures, society and culture, } \\
\text { science and technology, transports }\end{array}$ \\
\hline
\end{tabular}

Figure 3. Variables analyzed

\section{Results}

The empirical observation of the transcriptions highlighted three main groups of distinctive features: context-linked elements, paralinguistic and linguistic elements. The first category encompasses the type of delivery (impromptu, mixed, read), the length of speeches and the topic; among the paralinguistic elements, filled pauses, silent pauses, vowel lengthening, false starts and self-corrections and speed can be found; the lexical elements include opening and closing formulas, unmodified English loanwords, proper names and acronyms.

\subsection{Context-linked elements}

When analyzing an interpreter-mediated speech event and, in particular, a source speech, different parameters must be taken into consideration, starting from those related to the type of event and the context, which in turn affect other linguistic and paralinguistic variables, such as delivery pace, 
information density, level of technicality or incidence of speech disfluencies and carry-over effects (Schjoldager 1995a). A particularly detailed study on the different types of interpreted speeches is Alexieva's (1994), identifying several parameters such as the mode of production, the level of intertextuality with the other speeches within the same interpreted event and the use of non-verbal information (videos, slides, presentations, visual material, prosody, etc.).

Hönig's (2002) research project on source text type classification is characterized by a more didactic approach, since it was developed for teaching purposes, thus dividing texts into different levels of difficulty for speeches to be used in training; the parameters observed in this study include topic, structure, presence of numbers and figures, cohesion, coherence and speech presentation criteria: all these elements have an influence on the interpreting trainee's expectations and performance.

\subsubsection{Type of delivery}

Since the procedures of the plenary session entail a very limited allotted time per speaker (typically, 2 minutes per MEP, see $\S 2$ ), a large number of speeches have been prepared well in advance and thus they are written-to-be-read texts; other MEPs read a sort of script aloud, leaving very limited space for improvisation and spontaneous speech; this setting and context-linked characteristic is well represented in the sample of speeches that have been analyzed (fig. 4):

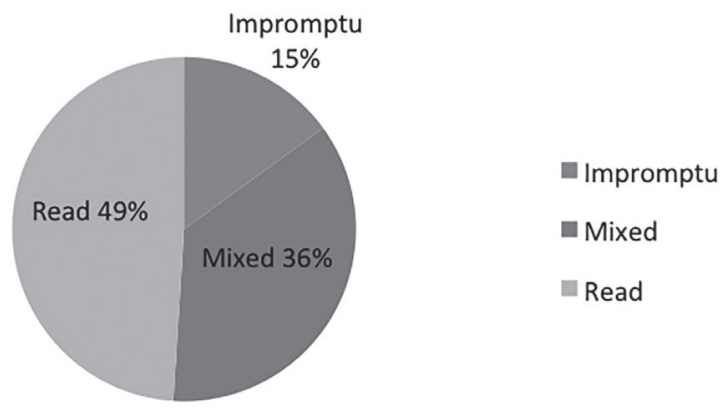

Figure 4. Speeches per type of delivery

The strong incidence of texts written-to-be-read cannot but affect the prosody (Alexieva 1994, Iglesias Fernández 2011), bringing about less redundancy, fewer repetitions and a more complex syntax than in spontaneous speech. All these elements also have implications on the number of (filled and silent) 
pauses as well as on speed, thus raising a question: what kind of orality model can be used as a reference for the EP plenary session?

Several studies have focused on the relationship between lexical density, understood as the measure of content per functional and lexical units in total (Russo, Bendazzoli \& Sandrelli 2006), and the type of delivery; Stubbs (1996) in his study on corpora and lexical semantics shows that there is a considerable difference in lexical density between written texts and oral speeches: $40-65 \%$ for the former and $34-58 \%$ for the latter. More specifically, moving to EPIC, different studies (Russo, Bendazzoli \& Sandrelli 2006 and Sandrelli, Bendazzoli \& Russo 2010) demonstrate that there is a difference in lexical density not only between written and spontaneous speech, but also among different languages: in EPIC, it is estimated around 58-59\% for Italian, 57\% for English and 53-54\% for Spanish. Brown \& Fraser (1979) and Keenan (1978) were among the first scholars theorizing that planned or unplanned speech can entail a different level of orality, highlighting "a number of syntactic and discourse structure differences":

unplanned discourse more than planned relies on the immediate context, rather than on syntax, to express propositions; hence there is referent deletion and especially the deletion of pronouns, left dislocation and avoidance of syntactic subordinators[...]. [Keenan] also finds greater reliance on deictic modifiers, avoidance of relative clauses, avoidance of the passive voice, reliance on the present tense, and repetition, both lexical and phonological. [...] Formal scenes often demand planned discourse, and conversely planned discourse may have some of the metaphorical connotations of formal scenes and may be used, in ways paralleling code-switching phenomena, to convey a shift to distancing or formality. (Brown \& Fraser 1979: 50)

Therefore, the type of delivery can also have an impact on the understanding of the source speech and can often be related to a different segmentation in information units, leading the interpreter/listener to the activation of different information processing patterns, thus inevitably affecting the target speech (Balzani 1990 and Hönig 2002). In conclusion, in written-to-be-read texts, communication is poised between different diamesic varieties, between writing and orality.

\subsubsection{Speech length}

In a complex institutional context such as the EP plenary session, the variables at play are manifold; Alexieva (1997), among others, presents a classification of interpreted events on the basis of various parameters, such as mode of delivery, participants, topic, strategies and spatial-temporal constraints, which are often linked to the goal of the event. In the plenary session, being the last 
step in the complex legislative process, the main objective is not having a smooth flow of communication, but rather developing the very last phase of discussion and vote on a report or a piece of legislation that has already been drafted in the previous stages.

The evolution of the EP from a setting for mainly epideictic discourse to a forum for negotiation on actual legislation could be followed through from the House's verbatim reports through the years. Interestingly, comments to the effect that "eloquence has been lost" are sometimes heard among interpreters. (Marzocchi 1998: 69)

These effects on the quality of speech are undoubtedly linked to temporal constraints, since the allotted time, above all for MEPs, is fairly limited (around 2 minutes); turn-taking is scheduled well in advance and the longest speeches are the exclusive prerogative of a small number of institutional figures, such as rapporteurs, Commissioners, representatives of the Council or particularly eminent guests. That is why the representation of the speeches' length in the corpus reflects this division (fig. 5):

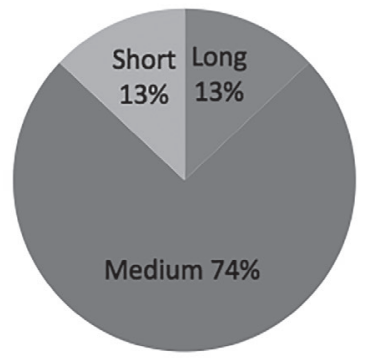

\author{
a Short $<300$ words \\ Medium 301-1000 \\ words \\ Long $>1000$ words
}

Figure 5. Length of speeches

The chart clearly shows that, despite the small number of long speeches, the average number of words (301-1000 words) is fairly high, considering that for many of those speeches the time allotted is very limited. Once again, these figures confirm the hypothesis of a very high lexical density and delivery speed.

\title{
4.1.3. Topic
}

The institutional setting strongly influences this parameter, which follows the EPIC sub-division of topics (Agriculture and Fisheries, Economics and Finance, Justice, Health, Science and Technology, Environment, Politics); as stated above, the actual organization of the plenary session leaves little space for real and spontaneous debate, thus affecting the topic (Marzocchi 1998) (fig. 6): 


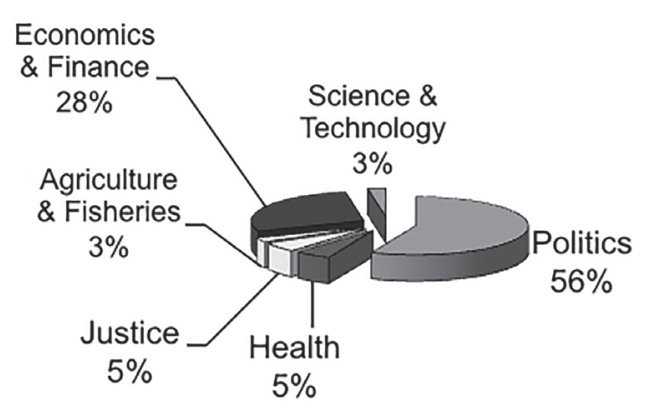

Figure 6. Topics

Communication patterns are clearly influenced by the fact that the plenary session is the very last step of the law-making process, therefore the main topic is often related to a limited number of macro-areas; that is why interpreters are usually provided with all the documents (laws, regulations, items on the agenda, etc.) in advance in order for them to prepare for an assignment that, due to the specific constraints of this setting, is one of the most challenging:

A further point of interest is the extent to which these difficulties interact with the interpreter's grasp of the knowledge shared by speaker and audience. At this stage, it depends on availability of documents, as was seen with reference to committee meetings, and increasingly on previous exposure to other stages of the same dossier; exposure may date back several weeks or months, which hints at issues such as the activation stored in the long-term memory. (Marzocchi 1998: 70)

\subsection{Paralinguistic elements}

\subsubsection{Filled pauses}

Interpreting Studies literature is particularly rich in studies on pauses and their different characteristics. The first attempt at classifying pauses dates back to Duez (1982), dividing them into "silent" and "filled" pauses respectively, where the latter is actually made of several additional sub-divisions of "non-silent pauses", including false starts and repetitions. Similarly, O'Connel and Loui (1979) studied the role of these paralinguistic elements and their stylistic effect, which is of particular relevance in spontaneous but also in written-to-be-read speech. More recent research (Tissi 2000, Mead 2000, Gòsy 2007 and Bakti 2009) demonstrates that considerable attention is currently being attached to this paralinguistic feature by scholars and professionals. 
More specifically, Tissi (2000) provides a particularly detailed classification of silent pauses (among which we can find initial pauses, conjunction pauses or pauses within the same sentence) and disfluencies (filled pauses, parenthetic pauses, interruptions, repetitions, corrections and false starts). All these phenomena have multiple functions: they can be traces of cognitive activity associated to a particularly difficult segment, but also functional elements, and they all have an impact on message reception (delivery speed, information density, etc.).

Going back to our corpus, filled pauses have been identified following Tissi's (2000) definition (disfluency associated to the emission of vowel sounds) and indicated in the transcriptions with the symbol "ehm". An example is provided hereunder:

[/e soprattutto ehm si sono ridotte negli anni le differenze/].

In the sample of speeches that have been analyzed, 123 filled pauses have been detected, with an incidence of 0.69 phenomena per minute of speech. It must not be forgotten that "pauses are also an important phenomenon revealing mental operations and hesitation due to cognitive effort" (Ahrens 2002: 42).

\subsubsection{Silent pauses}

Among the various paralinguistic elements that have been observed, it is worth mentioning silent pauses, whose meaning, function and incidence can vary considerably depending on a number of rhetorical and stylistic factors. The definition that has been taken as a benchmark is Bakti's (2009): a pause exceeding 0.3 seconds without the emission of sounds between two linguistic units; they have been indicated in the transcription with the symbol "...", as in the example:

[/ perché ... a volte anzi molto spesso diventare anziani significa rischiare di diventare più poveri?/]

As it is clear in the example above, this type of paralinguistic phenomenon can also "contribute to discourse segmentation and help give prominence to particular text samples, drawing the listener's attention to certain elements and making it easier [...] to understand" (Tissi 2000: 107). Therefore it cannot always be considered a disfluency as such, but rather a rhetorical device which can help in the disambiguation of syntax as well (Mazzetti 1998).

One hundred and twenty-five phenomena have been detected in the corpus, with an overall incidence of 0.71 per minute of speech. The frequency of silent pauses is fairly similar to the case of filled pauses, therefore it can be 
speculated that these paralinguistic elements may have a similar role in this context.

\subsubsection{Vowel lengthening}

Another phenomenon that can be classified both as a disfluency and a rhetorical device is vowel lengthening, which, in Cecot's definition (2001), is a filled pause over 0.3 seconds with the emission of vowel sounds that are not separated from the previous linguistic units. In the transcription it has been indicated with the symbol ":", as in:

[/ già introdotta negli Stati Uniti dieci anni fa: ... l'ethic officer]

In the corpus, the incidence of these phenomena is considerably lower if compared to the previous paralinguistic elements: only 13 occurrences have been registered, with a global incidence of 0.07 phenomena per minute of speech. Once again, this may be explained by the fact that "syllable lengthening may have a function of discourse scansion. [...] The lengthening of the tonic vowel of a following word has the function of drawing attention back to an important informative event" (Tissi 2000: 118).

\subsubsection{False starts and self-corrections}

The last types of disfluency that have been observed were false starts and self-corrections, intended as the repetition of the initial sound of a word or the corrective repetition of a linguistic segment, which have been indicated in the transcription with the symbol "-":

[/ l'ultima frase del considerando ventitre a sia rie- reintrodotta/]

In the corpus, 120 phenomena have been identified, with an overall incidence of 0.68 per minute of speech. As highlighted by Hieke (1981), the researcher/ observer must adopt an integrated approach when analyzing these paralinguistic elements, indicating that one cannot just observe the disfluency per se, but must also consider the previous and following linguistic units.

\subsubsection{Speed}

Among the many variables that must be considered when analyzing this kind of oral texts, speed of delivery is certainly one of the most influential; temporal constraints have always been carefully studied since Gerver, in his 1975 research, stated for the first time that the optimal speed for the source speech (which he calls "stimulus texts") is around 100 words per minute and an increase in stimulus speed also increases the cognitive load for interpreters, 
resulting in a higher rate of errors and omissions. In different studies conducted in the same period (Seleskovitch 1978, Lederer 1981) it was shown that, in the case of written-to-be-read speech - what Changshuan (2010) calls "recited speech" - since the incidence of hesitations and redundancy is considerably lower than in spontaneous speech, the maximum rate to ensure quality should be 100 words per minute. The following is a comment taken from the message board of the International Association of Conference Interpreters (AIIC): ${ }^{4}$

We all know that a speaker speaking at about 100 to 120 words per minute is perfectly acceptable. However, there are exceptions to this: dense originals without much redundancy. Such speeches may seem excessively fast even if presented at 120 words per minute.

Several studies have demonstrated that excessive speed of delivery is often associated with cognitive load problems, disfluencies and errors; in particular, Comesaña Losada (2003) relates speed with loss of information and disfluencies in the target speech, establishing a clear cause-effect relationship between the two.

In EPIC, the average speed of delivery for original Italian speeches is 130 words per minute (Bendazzoli 2010); more specifically, in our corpus, the distribution of speech rate is the following (fig. 7):

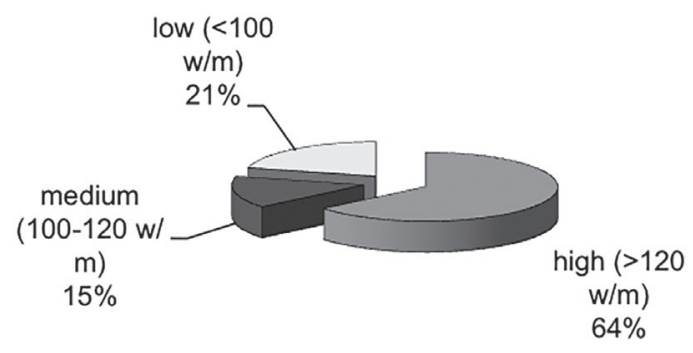

Figure 7. Speed

These figures seem to corroborate Marzocchi's (1998: 70) hypothesis for which, in the plenary session, "the speed of delivery, as imposed here by the sometimes ridiculously short speaking times" is one of the main problems that interpreters must cope with.

4. Communicate (1999). AIIC Webzine $n^{\circ} 1$. Online at http://www.aiic.net/ViewPage.cfm/ article13 (consulted 27.03.2015) 


\subsection{Lexical elements}

In line with Alexieva's (1994) model representing the four main levels for the simultaneous interpreting process, context-linked and paralinguistic elements (speed, number of pauses, their length and function, pronunciation and prosody, etc.) are followed by the linguistic level, which, in the aforementioned model, can be divided into three parts: morphological, syntactic and lexical; when it comes to analysing the latter in such a complex context as the EP plenary session, it is not enough to consider the use of language for special purposes (LSP) (Niska 1999) and the existence - if any - of a European jargon as defined by Goffin (1994), among others:

Qu'il donne lieu à la création de mots nouveaux (euronymes) pour désigner des concepts en devenir ou qu'il transmette des notions et des désignations enracinées dans chacune des langues protagonistes (hétérolexies), ce langage est constitué d'un vaste ensemble d'énoncés qui fonctionnent normalement [...] comme un sous-système au sein d'une langue et non pas comme une langue artificielle, ni un jargon, forme dégradée ou corrompue, d'une langue "nationale". (Goffin 1994: 7)

More specifically, in the case analyzed here, it is also necessary to take into consideration a set of language-specific lexical elements that go beyond the debate on the existence of a European jargon as such. The present corpus shows that, in addition to the context-linked and paralinguistic features, the Italian spoken within the EP plenary session presents some lexical peculiarities as well, ranging from specific opening/closing formulas to the use of loanwords and proper names/acronyms. Here are some examples taken from the corpus.

\subsubsection{Opening formulas}

If, on the one hand, the use of opening (and closing) formal expressions is carefully regulated in public and private correspondence by the REI Network (Rete per l'Eccellenza dell'Italiano Istituzionale ${ }^{5}$ ), providing a detailed list of conventions on the use of non-discriminatory language, transliteration, acronyms, abbreviations, punctuation, italics and capital letters, symbols and geonomenclature, on the other hand very few indications are provided for spoken language; the lack of specific guidelines on the proper use of institutional spoken Italian, which is undoubtedly more complex to regulate, has led

5. http://ec.europa.eu/translation/italian/rei/index_it.htm (last consulted 30/03/15) 
to a great diversity even in the use of apparently easier expressions: opening formulas.

More specifically, analysing the most common ways of addressing the EP plenary assembly, the most frequently mentioned institutional figures and the most frequently used ways of starting an important speech, and one that is often prepared well in advance, is of particular relevance not only for the interpreter, who has to cope with several problems in this setting, thus being required to use "standardized" formulas to start with, but also for anybody who is interested in the evolution of institutional spoken Italian and its social value. There is no doubt that the EP represents an unprecedented showcase not only for the Italian language and culture, but it is also a mirror of the complex social values attached to the use of institutional spoken language.

Going back to the corpus, the most common opening formulas that have been found (fig. 8) are:

- Grazie Presidente

- Signor presidente

- Onorevoli parlamentari

- Signor Presidente della Commissione, io risponderò un attimo soltanto

- Grazie signora Presidente

- Signor Presidente del Consiglio irlandese

- La ringrazio Presidente

- Grazie signor Presidente

- Signor Commissario

- Egregi colleghi

- Signor Presidente del Parlamento
- Signor Presidente del Consiglio

- Signor Presidente arrivo subito al punto

- Presidente

- Signor Presidente incaricato

- Signor Presidente designato della Commissione europea

- Cari colleghi

- Signor Commissario

- Onorevoli deputati

- Grazie signor Commissario

- Colleghi

- Signori commissari

Figure 8. List of opening formulas

The data collected shows that $70 \%$ of the opening formulas are direct addresses to the President, as in consolidated practice, $15 \%$ of them are also addressed to the colleagues and another $15 \%$ to the Commissioner(s); interestingly, among the $70 \%$ of speeches in which the speaker directly mentions the President, 8 cases also provide the specific institutional role and 2 of them contain meta-comments ("Signor Presidente, io risponderò un attimo soltanto" / "Signor Presidente arrivo subito al punto"). These meta-comments are particularly relevant because they point out that the speaker is perfectly aware of the turn-taking mechanisms and allotted time rules within the plenary session, but he or she feels the need to inform the audience that his/ her speech will be short and focused on the main item on the agenda. Being aware of the most frequent opening formulas and meta-comments is particularly useful for interpreting trainees, who may be asked to cope with other 
difficulties in the speech and therefore they need to be provided with solid strategies to be able to start their delivery by using automatized expressions:

Il riconoscimento di elementi linguistici ostici, la loro classificazione assieme all'elaborazione di soluzioni permette di costituire una riserva di strategie alle quali gli studenti possono attingere ogni qual volta si trovino ad affrontare un problema analogo, dato che, all'inizio dello studio di interpretazione, non hanno ancora sviluppato degli automatismi interpretativi - indispensabili per alleggerire lo sforzo cognitivo e distribuire opportunamente le proprie risorse. (Gran and Riccardi 1997: 12)

\subsubsection{Closing formulas}

Unlike opening formulas (which are more or less "institutionalized"), proper rhetorical expressions to formally conclude one's speech are not always present in our corpus; once again, one of the possible explanations for this phenomenon has to be found in the limited allotted time that the MPs must stick to, which is sometimes so short that the President is forced to interrupt the speaker and in some cases the microphone is cut off.

The rules governing speaking time within the EP plenary session are particularly complex given the diversity and the number of subjects involved in the democratic process, and they are based on the following criteria:

a first fraction of speaking time is divided equally amongst all the political groups, then a further fraction is divided among the groups in proportion to the total number of their members. MEPs who wish to speak are entered on the list of speakers in an order based on the numerical size of their group. However, a priority speaking slot is given to the rapporteurs of the committees responsible and to drafts men of other committees asked for an opinion. ${ }^{6}$

In the light of the aforementioned contextual elements, it may not be surprising that many Italian (and not only) MPs often stop their speeches in medias res, without any actual standardized closing formula, which is often the case for other conference or institutional settings. A particularly interesting research by Bendazzoli (2010) shows that opening and closing formulas in a conference setting are not only key to the whole event, in addition to being very easy to identify, with a clear objective and a set of more or less "standardized" expressions, but they can also share the same communicative intention; therefore, it is paramount to provide interpreting trainees with specific tools for the consolidation of the most frequent procedural formulas for comprehension and production (Bendazzoli 2010). The same conclusion

6. http://www.europarl.europa.eu/aboutparliament/en/20150201PVL00011/How-Plenaryworks (last consulted 30/03/15) 
can be drawn for the case of the EP plenary session: such a well-established democratic mechanism can provide recurring patterns that may be used for other settings as well.

Going back to the specific case being analysed, the limited number of proper closing formulas used by Italian speakers in the corpus shows a strong tendency to end with a generic appreciation remark: unspecific thanks account for $81 \%$ of the cases, whereas in $16 \%$ of them a specific "thank you" is addressed to the President. Interestingly, in 3\% of the cases a meta-comment was found; here is an example: "mi scuso col Presidente veramente perché ho visto solo adesso il tempo superato". If, on the one hand, a meta-comment would be more predictable in an opening formula since there is a need to attract the listener's attention in order to establish a relation of confidence with the recipients and to underline that the speaker knows the rules governing that particular institutional context (i.e., stick to the allotted time), on the other hand, meta-comments related to time at the end of a speech may be more unexpected. Face-threatening acts can be tackled with anticipation or repair strategies (Brown \& Levinson 1978): it is evident that the speaker who resorts to the aforementioned meta-comment as a closing formula is opting for an anticipation-based strategy.

\subsubsection{Unmodified English loanwords}

As the corpus analysis becomes more and more focused on the specific characteristics of this particular kind of institutional spoken Italian, the results of the observation become more and more language-bound, social-related and culture-specific. In particular, the decision to investigate the presence of unmodified English loanwords has its basis in the social value that has been attached to this linguistic phenomenon over the last few decades. A considerable number of studies have been devoted to this often debated topic - unlike other linguistic disputes, the apparent "invasion" of neologisms in Italian has generated a strong debate not only in the academic world - but little attention has been given to the actual use of these loanwords in the institutional spoken language (whereas, for writing, several guidelines have been provided by the entities in charge of standardizing the use of language in some specific contexts ${ }^{7}$ ).

In borrowing a foreign term, the degree of formal adaptation from the source to the target language may vary considerably. The two opposite strategies are generally dealt with as "adaptation" vs "adoption" (Hock \& Joseph

7. See Rete per l'Eccellenza dell'Italiano Istituzionale http://ec.europa.eu/translation/italian/ rei/index_it.htm (last consulted 30/03/15) 
1996). In the present paper, the term "unmodified loanword" indicates any adoption-based pattern simply transferring the term from the source to the target language, without any adaptation to the morphological and phonological system of the latter. This kind of borrowing is not only fairly easy to identify (in the plenary session reports, an unmodified English loanword stands out from the rest of the Italian text), but it is also one of the borrowing phenomena that most affects comprehension, production and pronunciation.

The analysis of this lexical phenomenon in our corpus was conducted by compiling a list of the most frequent unmodified English loanwords; hereunder are the most common ones (fig. 9):

- Governance, leadership.

- Bond, WTO.

- Roadmap, off-shore, partner, UNDP.

- Property right, budget, quickstart, management, default, media, leader, intelligence, follow-up.

Figure 9. Ranking of the most frequent unmodified English loanwords

As the results clearly show, there is a tendency by Italian speakers to resort to foreign words especially if these are associated with plenary session procedures, demonstrating that the English term has almost completely replaced the corresponding Italian version which, however - it is worth pointing out - do exist (management - gestione, leadership - guida, etc.). Among the most frequent results are also some proper names and abbreviations (WTO, UNDP) which stand for the English term, very often replacing the official Italian equivalent (OMC - Organizzazione Mondiale del Commercio) or even bypassing the official translation (unlike other languages such as Spanish or French, using the abbreviation PNUD - Programa de las Naciones Unidas para el Desarrollo, Programme des Nations Unies pour le Développement: in Italian the English acronym has taken over from the very beginning).

In spoken language, these particularly interesting phenomena affect not only the lexical and morphological level, but first and foremost the level of pronunciation; countless examples of mispronounced unmodified English loanwords have emerged from the Italian speakers' original audio files. The evident lack of proximity between English and Italian from a morphological but also phonological point of view often brings about interesting examples of Italian speakers mispronouncing these borrowings, thus making comprehension particularly difficult. Here are some examples taken from the corpus: 


$$
\text { roadmap </rmal }>\text {, management </ma'nadzment/> }
$$

Even if frequently used within the plenary session, these loanwords - if mispronounced - may cause evident comprehension problems, especially considering the particularly complex setting, already accounting for several challenging variables (very high speech rate, written-to-be-read texts, high information density, specialized use of language, very short speaking time per MP, etc.). Adding one more difficulty to such a complex multi-lingual scenario (not to mention the number of language combinations involved in the plenary session) can be very challenging for interpreters. It must not be forgotten that inserting one word from a third language (English) in addition to the pair of languages involved in simultaneous interpreting (Italian-Spanish in this case) entails extra cognitive efforts for the interpreter, since his/her activity per se represents:

una violazione del principio di separazione delle lingue, secondo il quale la lingua utilizzata in un determinato momento provoca una parziale inibizione sulle altre lingue conosciute dall'interprete. (Gran 1989: 189)

Moreover, the fact that all interpreters working at the EP understand and speak English should not be taken for granted, even if they must be familiar with some terms regarding the most common procedures and internal mechanisms.

However, it is not necessary to analyse the possible difficulties for the interpreter to see that the strong presence of unmodified English loanwords in spoken Italian (and, in particular, in institutional Italian) implies a set of challenging issues even in the source language. If we analyse the original Italian speech, it is easy to realise that the presence of these borrowings often brings about some problems in the linguistic units that immediately follow this lexical element: in particular, the number of disfluencies and carry-over effects (Schjoldager 1995b, Gòsy 2007) is higher than in other parts of the same speech. Therefore, it can be speculated that these phenomena indicate a cognitive overload in the speaker due to the presence of an unmodified foreign term.

\subsubsection{Proper names and acronyms}

When analysing spoken language in view of a simultaneous interpreting task, the presence of other challenging lexical elements cannot be neglected, in particular proper names, acronyms and culture-bound references (Amato $\&$ Mack 2011), which are widely recognized as major problem-triggers not only in interpreting but also in translation: 
[proper names] can carry implicitly a wealth of additional information immediately available to a native speaker, but mostly obscure for foreigners - e.g. ethnic origin, social class, speaker attitude or the relationship between different people. Names can play any kind of functions, from communicative to vocative, expressive, deictic and ideological. (Amato \& Mack 2011: 52)

Another important aspect that must be considered is that the semantic content of proper names and acronyms can be extremely limited, thus the listener (and the interpreter) "non ha molte possibilità di inferire il significato, come invece può fare nel caso di un'espressione complessa" (Medici 2006: 105).

From a closer look at the results of our study, these are the most frequent groups of proper names and acronyms that have been found in the Italian speeches (fig. 10):

- Names of colleagues, presidents, commissioners, rapporteurs (relatrice Fourtou, commissario Lamy, onorevole Fiori).

- Names of politicians and political groups.

- Finance and technology acronyms (OGM, PIL).

- Procedures, projects, laws (Agenda di Lisbona, Progetto Erasmus).

- Newspapers, magazines (Financial Times, Norte de Castilla).

- Companies (Parmalat, Enron).

- Historical figures (Ignazio da Loyola).

- International organizations (WTO, UNDP, EBA).

Figure 10: most frequent groups of proper names and acronyms

As stated in the previous section, there is a clear tendency by Italian speakers towards the use of English acronyms (WTO, EBA, etc.) instead of the Italian equivalents; moreover, it must be considered that proper names and acronyms are often comprehension problem-triggers, regardless of the fact that, in a specific setting such as the EP plenary session, the speaker and the recipient share the same level of knowledge and expertise (this should be the case of interpreters as well, but obviously, there is always a gap between the participants involved in the communications and the interpreter). When analyzing these phenomena, it must be reminded that:

The use of proper names allows the speaker to present his/her relation to and knowledge of the referenced entities as well as his/her assumptions about the other participants' knowledge and familiarity with the subject. If the speaker's assumption about the listener's knowledge is false, and if the knowledge conveyed by the speaker in early portions of the conversation does not allow the listener to bypass the knowledge deficit, the proper name automatically becomes a source of trouble for the continuing conversation. (Meyer 2008: 107) 


\section{Conclusions}

The analysis conducted on a small corpus of oral texts delivered by Italian speakers within the EP plenary session confirms the hypothesis that we are dealing with a microlanguage, with its specific context-linked, paralinguistic and lexical characteristics. The most relevant ones have been found in the high number of written-to-be-read texts (entailing specific prosody and challenges for the interpreter, since the typical features of orality in spontaneous speech are not present), the prevalence of short speeches with a very specific topic (speaking time, turn-taking and items on the agenda are planned well in advance), the strong incidence of filled and silent pauses as well as false starts and self-corrections despite the very high speech rate (thus accounting for a particularly high information density), the recurring presence of unmodified English loanwords even in the use of acronyms and abbreviations (regardless of the topic being discussed), and the tendency to resort to specific opening and closing formulas, requiring a good knowledge of the EP procedures.

This setting poses significant challenges for the listener as well as the interpreter, since there is no actual spontaneous debate at this stage and often sparse attendance, therefore the "subjective limit of what can actually be interpreted is sometimes reached" (Marzocchi 1998: 70). In order to cope with these challenges, a number of strategies can be developed, such as the exposure to the previous stages of the piece of legislation being debated and the study of documents regarding the items on the agenda, activating a set of knowledge and skills that had been stored in the long-term memory.

The constraints and the challenges of this setting make these oral texts particularly difficult to be used as didactic material for interpreting trainees. However, studying Italian source speeches and their main features in such a complex setting, characterized by extremely marked phenomena, can shed light on specifically tailored strategies, ranging from cancellation of some parts of the speech, to generalization, reformulation, use of synonyms, adaptation and expansion (Bertozzi in press: 5). Future research could give an important contribution to their study, starting from the analysis of this microlanguage and further exploring its didactic perspective with a view to simultaneous interpreting which, in any case, must be based on this essential consideration: a good target speech cannot disregard a good knowledge of the source speech and its specific orality-bound characteristics. 


\section{References}

AHrENS, Barbara. (2002) "The interdependence between verbal and nonverbal elements in SI." In: Garzone, Giuliana; Peter Mead \& Maurizio Viezzi (eds.) 2002. Perspectives on interpreting. Bologna: Clueb, pp. 37-46.

AlexieVA, Bistra. (1994) "Types of Texts and Intertextuality in Simultaneous Interpreting." In: Snell-Hornby, Mary; Franz Pöchhacker \& Klaus Kaindl (eds.) 1994. Translation Studies: an Interdiscipline. Selected papers from the Translation Studies Congress (Vienna) September, 1992. Amsterdam: John Benjamins, pp. 179-189.

AlexievA, Bistra. (1997) "A Typology of Interpreter-Mediated Events." The Translator 3:2, pp. 153-174.

AmATO, Amalia \& Gabriele Mack. (2011) "Interpreting the Oscar night on Italian tv: an interpreters' nightmare?" The Interpreter's Newsletter 16, pp. 37-60.

ANGElelli, Claudia. (2000) "Interpretation as a Communicative Event: A Look through Hymes' Lenses." Meta 45: 4, pp. 580-592.

BAKTI, Maria. (2009) "Speech Disfluencies in Simultaneous Interpretation." In: Crom, Dries de (ed.) 2009. Translation and the (Trans)formation of Identities: Selected Papers of the CETRA Research Seminar in Translation Studies 2008. Electronic version: <http://www.arts.kuleuven.be/cetra/papers>.

BALZANI, Maurizio. (1990) "Le contact visuel en interpretation simultanée: Resultats d'une experience (français-italien).” In: Gran, Laura \& Christopher Taylor (eds.) 1990. Aspects of Applied and Experimental Research on Conference Interpretation. Proceedings of a conference held in 1989. Udine: Campanotto, pp. 93-100.

Bendazzoli, Claudio. (2010) Testi e contesti dell'interpretazione di conferenza: uno studio etnografico. Bologna: Asterisco.

Bernardini, Silvia; Adriano Ferraresi \& Maja Miličević. (Forthcoming) "From EPIC to EPTIC: Building and using an intermodal corpus of translated and interpreted texts." Unpublished paper presented at the 46th Annual Meeting of the Societas Linguistica Europea (SLE 2013) Split, Croatia. 18-21 September.

BERTOZZI, Michela. (in press) "Un intruso en cabina: los retos del anglicismo en la interpretación entre italiano y español." In: Proceedings of the 27th AISPI Conference, Forlì 23-26/05/2012.

Brown, Penelope \& Colin Fraser. (1979) "Speech as a marker of situation." In: Giles, Howard \& Klaus Scherer (eds.) 1979. Social markers in speech. Cambridge: Cambridge University Press, pp. 33-62.

Brown, Penelope \& Stephen Levinson. (1978) Politeness: Some universals in language usage. Cambridge: Cambridge University Press. [First published 1978 as part of Ester N. Goody (ed.): Questions and Politeness]. 
CAMBiaghi, Bona. (1988) "La ricerca nell'insegnamento delle microlingue. Stato attuale." In: Il linguaggio delle scienze e il suo insegnamento. Brescia: La Scuola, pp. 45-56.

CECOT, Michela. (2001) "Pauses in simultaneous interpretation." The Interpreter's Newsletter 11, pp. 63-85.

ChANGSHUAN, Li. (2010) "Coping strategies for fast delivery in simultaneous interpretation." Jostrans, The Journal of Specialised Translation 13, pp. 19-25.

COMESAÑA LOSADA, Nuria. (2003) "A velocidade do discurso orixinal: un estudio empírico sobre a sua influencia no rendemento dos intérpretes." In: Alonso Bacigalupe, Luis (ed.) 2003. Investigación experimental en interpretación de linguas: primeiros pasos. Vigo: Universidade de Vigo, pp. 81-101.

DEFRANCQ, Bart. (2015) "Corpus-based research into the presumed effects of short EVS." Interpreting 17:1, pp. 26-45.

DuEz, Danielle. (1982) "Silent and non-silent pauses in three speech styles." Language and Speech 25:1, pp. 11-28.

GERVER, David. (1975) "A Psychological Approach to Simultaneous Interpretation." Meta 20:2, pp. 119-128.

GofFIN, Roger. (1994) "L'eurolecte: oui, jargon communautaire: non.” Meta 39:4, pp. 636-642.

GòsY, Maria. (2007) "Disfluencies and Self-monitoring." Govor 26, pp. 91-110.

GRAN, Laura. (1989) "Interdisciplinary research on cerebral asymmetries: significance and prospects for the teaching of interpretation.” In: Gran, Laura \& John Dodds (eds.) 1989. The theoretical and practical aspects of teaching conference interpretation. Udine: Campanotto, pp. 93-100.

GRAN, Laura \& Alessandra Riccardi (eds.). (1997) Nuovi orientamenti negli studi sull'interpretazione. Trieste: Università degli Studi di Trieste.

HIEKE, Adolf. (1981) "A content-processing view of hesitation phenomena." Language and Speech 24:2, pp. 147-160.

Hock, Hans \& Brian Joseph. (1996) Language history, language change and language relationship. Berlin \& New York: Mouton de Gruyter.

HönIG, Hans. (2002) "Piece of Cake - or Hard to Take? Objective Grades of Difficulty of Speeches Used in Interpreting Training." In: Various authors. 2002. Teaching simultaneous interpretation into a 'B' language. Proceedings of the EMCI workshop on teaching simultaneous into a B language, held at ESIT in Paris in September 2002. Electronic version: http://www.emcinterpreting. org/?q=system/files/EMCI-TeachingSimultaneousIntoB-voll.pdf.

IgLESIAS FERnÁNDEZ, Emilia. (2011) "Stimme." In: Collados Aís, Ángela; Emilia Iglesias Fernández; Esperanza Macarena Pradas Macías \& Elisabeth Stévaux (eds.) 2011. Qualitätsparameter beim Simultandolmetschen: interdisziplinäre Perspektiven. Leipzig: Gunter Narr, pp. 33-34. 
KEENAN, Edward. (1978) "Some Logical Problems in Translation." In: Guenthner, Franz \& Monica Guenthner-Reutter (eds.) 1978. Meaning and Translation: Philosophical and Linguistic Approaches. London: Duckworth, pp. 157-189.

LEDERER, Marianne. (1981) La traduction simultanée - expérience et théorie. Paris: Minard.

MARzOCCHI, Carlo. (1998) "The case for an institution-specific component in interpreting research." The Interpreter's Newsletter 8, pp. 51-74.

MARzOCCHI, Carlo. (2005) "On a contradiction in the discourse on language arrangements in EU Institutions." Across Languages and Cultures 6:1, pp. 5-12.

Mazzetti, Andrea. (1998) Linflusso delle deviazioni segmentali e prosodiche sulla comprensione del testo di partenza in interpretazione simultanea. Trieste: Università degli Studi. Unpublished dissertation.

MEACCI, Federica. (2009) Numeri, nomi ed elenchi nell'interpretazione simultanea televisiva. Trieste: Università degli Studi. Unpublished dissertation.

MEAD, Peter. (2000) "Control of pauses by trainee interpreters in their A and B languages." The Interpreter's Newsletter 10, pp. 89-102.

MEDICI, Valentina. (2006) I nomi propri: una sfida per l'interprete. Bologna: Alma Mater Studiorum. Unpublished dissertation.

Meyer, Bernd. (2008) "Interpreting Proper Names: Different Interventions in Simultaneous and Consecutive Interpreting?" In: House, Juliane (ed.) 2008. Beyond Intervention: Universals in Translation Processes. Selected proceedings of the Panel "Beyond Intervention: Universals in Translation Processes", organized by Juliane House for the Second Conference of the International Association for Translation and Intercultural Studies (IATIS) held at the University of the Western Cape, South Africa, July 12-14, 2006. trans-kom 1:1, pp. 105-122. Electronic version: < http://www.trans-kom.eu/>.

NiSKA, Helge. (1999) "Quality Issues in Remote Interpreting." In: Alvarez Lugris, Alberto \& Anxo Fernandez Ocampo (eds.) 1999. Anovar/anosar. Estudios de traducción e interpretación.Vigo: Universidade de Vigo, pp. 109-121.

O' Connell, Daniel \& Wayne Loui. (1979) "Rhetorical pauses in oral reading." Language and Speech 22, pp. 397-405.

Russo, Mariachiara; Claudio Bendazzoli \& Annalisa Sandrelli (2006) "Looking for Lexical Patterns in a Trilingual Corpus of Source and Interpreted Speeches: Extended Analysis of EPIC (European Parliament Interpreting Corpus)." Forum 4:1, pp. 221-249.

Russo, Mariachiara; Claudio Bendazzoli; Annalisa Sandrelli \& Nicoletta Spinolo (2012) "The European Parliament Interpreting Corpus (EPIC): implementation and developments." In: Straniero-Sergio, Francesco \& Caterina Falbo (eds.) 2012. Breaking ground in corpus-based interpreting studies. Bern: Peter Lang, pp. 53-90. 
SANDrElli, Annalisa; Claudio Bendazzoli \& Mariachiara Russo. (2010) "European Parliament Interpreting Corpus (EPIC): Methodological Issues and Preliminary Results on Lexical Patterns in Simultaneous Interpreting." International Journal of Translation 22:1-2, pp. 165-203.

SCHJOldager, Anne. (1995a) "An Exploratory Study of Translational Norms in Simultaneous Interpreting: Methodological Reflections." Hermes: Journal of Language and Communication Studies 14, pp. 65-87.

SCHJOldager, Anne. (1995b) "Interpreting Research and the "Manipulation School' of Translation Studies." Target 7:1, pp. 29-45.

SElESKovitCH, Danica. (1978) "Language and Cognition." In: Gerver, David \& H. Wallace Sinaiko (eds.) 1978. Language Interpretation and Communication. Proceedings of the NATO Symposium on Language Interpretation and Communication held in Venice, September 26-October 1, 1977. New York: Plenum press, pp. 333-342.

SERIANNI, Luca \& Giuseppe Giuseppe (eds.). (2004) Manuale di Linguistica Italiana. Milan: Bruno Mondadori.

SETTON, Robin. (2011) "Corpus-based Interpretation Studies: Reflections and prospects." In: Kruger, Alet; Kim Wallmach \& Jeremy Munday (eds.) 2011. Corpus-based Translation Studies: Research and Applications. London: Continuum, pp. 33-75.

SPINOLO, Nicoletta. (2014) Il Linguaggio Figurato e l'Interpretazione Simultanea: il progetto IMITES. Bologna: Alma Mater Studiorum. Unpublished PhD dissertation.

STUBBS, Michael. (1996) Text and corpus analysis: computer-assisted studies of language and culture. Oxford and Cambridge: Blackwell Publishing.

STUBBS, Michael. (2001) Words and phrases: corpus studies of lexical semantics. Oxford: Blackwell Publishing.

Tissi, Benedetta. (2000) "Silent pauses and disfluencies in simultaneous interpretation: A descriptive analysis." The Interpreter's Newsletter 10, pp. 103-128.

TOGNINI BonELLI, Elena. (2001) "Functionally Complete Units of Meaning across English and Italian: Towards a Corpus-Driven Approach." In: Altenberg, Bengt \& Sylviane Granger (eds.) 2001. Lexis in Contrast. Corpus-Based Approaches. Amsterdam \& Philadelphia: John Benjamins, pp. 73-96. 


\section{BIONOTE / NOTA BIOGRAFICA}

Michela Bertozzi is a PhD student at the Department of Interpreting and Translation of the University of Bologna at Forli and she also works as a freelance conference interpreter and translator (languages: Italian, Spanish, English). She graduated in Conference Interpreting from the same University and she is currently involved in Simultaneous and Consecutive Interpreting teaching between Spanish and Italian at the MA Course in Interpreting of the University of Bologna at Forlì. Her main research interests encompass contact linguistics, corpus-based interpreting studies, simultaneous and consecutive interpreting between Spanish and Italian and the presence of English loanwords.

Michela Bertozzi è dottoranda del Dipartimento di Interpretazione e Traduzione del Campus di Forlì, oltre che interprete e traduttrice (lingue di lavoro: italiano, spagnolo e inglese). Laureata in Interpretazione, si occupa di didattica dell'interpretazione tra italiano e spagnolo per il corso di Laurea Magistrale in Interpretazione dell'Università di Bologna (Campus di Forlì). I principali interessi di ricerca sono legati alla linguistica di contatto, gli studi basati sui corpora, l'interpretazione simultanea e consecutiva tra italiano e spagnolo e la presenza di anglicismi. 